\title{
A Low-Cost Optoacoustic Sensor for Environmental Monitoring
}

\author{
Antonios Stylogiannis ${ }^{1,2,+}$, Nikolaos Kousias ${ }^{3,+}$ (D) , Anastasios Kontses ${ }^{3}$, Leonidas Ntziachristos ${ }^{3}$ (D) \\ and Vasilis Ntziachristos ${ }^{1,2, *}$ \\ 1 Technical University of Munich, School of Medicine, Chair of Biological Imaging, 80333 Munich, Germany; \\ stylogiannis@helmholtz-muenchen.de \\ 2 Helmholtz Zentrum München $(\mathrm{GmbH})$, Institute of Biological and Medical Imaging, \\ 85764 Neuherberg, Germany \\ 3 Mechanical Engineering Department, Aristotle University of Thessaloniki, P.O. Box 458, \\ GR 54124 Thessaloniki, Greece; nkousias@auth.gr (N.K.); akontses@auth.gr (A.K.); leon@auth.gr (L.N.) \\ * Correspondence: bioimaging.translatum@tum.de \\ + These authors contributed equally to this work.
}

\section{check for}

updates

Citation: Stylogiannis, A.; Kousias, N.; Kontses, A.; Ntziachristos, L.; Ntziachristos, V. A Low-Cost Optoacoustic Sensor for Environmental Monitoring. Sensors 2021, 21, 1379. https://doi.org/ $10.3390 /$ s21041379

Received: 8 January 2021

Accepted: 11 February 2021

Published: 16 February 2021

Publisher's Note: MDPI stays neutral with regard to jurisdictional claims in published maps and institutional affiliations.

Copyright: (c) 2021 by the authors. Licensee MDPI, Basel, Switzerland. This article is an open access article distributed under the terms and conditions of the Creative Commons Attribution (CC BY) license (https:/ / creativecommons.org/licenses/by/ $4.0 /)$.

\begin{abstract}
Attention to Black Carbon (BC) has been rising due to its effects on human health as well its contribution to climate change. Measurements of BC are challenging, as currently used devices are either expensive or impractical for continuous monitoring. Here, we propose an optoacoustic sensor to address this problem. The sensor utilizes a novel ellipsoidal design for refocusing the optoacoustic signal with minimal acoustic energy losses. To reduce the cost of the system, without sacrificing accuracy, an overdriven laser diode and a Quartz Tuning Fork are used as the light source and the sound detector, respectively. The prototype was able to detect $\mathrm{BC}$ particles and to accurately monitor changes in concentration in real time and with very good agreement with a reference instrument. The response of the sensor was linearly dependent on the BC particles concentration with a normalized noise equivalent absorption coefficient (NNEA) for soot equal to $7.39 \times 10^{-9} \mathrm{~W} \mathrm{~cm}^{-1} \mathrm{~Hz}^{-1 / 2}$. Finally, the prototype was able to perform $\mathrm{NO}_{2}$ measurements, demonstrating its ability to accurately monitor both particulate and gaseous pollutants. The proposed sensor has the potential to offer a significant economic impact for BC environmental measurements and source appointment technologies.
\end{abstract}

Keywords: photoacoustic; soot; black carbon; $\mathrm{NO}_{2}$; QTF; miniaturized; QEPAS; exhaust gas

\section{Introduction}

Black Carbon (BC) is an important component of atmospheric particulate matter that has been recently attracting increased attention by the scientific community due to its effects on human health and the climate [1,2]. Regarding human health, BC concentration has been well-correlated with all-cause mortality as well as cardiovascular mortality and morbidity, due to its capacity to carry a wide variety of toxic chemicals [3,4]. Regarding its effects on the climate, $\mathrm{BC}$ is now considered to be the second most influential climate-altering agent next to $\mathrm{CO}_{2}[1,5]$ due to its high light absorption. Its effect is particularly important in remote snow or ice-covered areas (the Arctic, Himalayas, etc.) where it affects the albedo of the surface [6,7]. In contrast to $\mathrm{CO}_{2}, \mathrm{BC}$ is considered a short-lived climate-relevant species, rendering it an immediate target of regulation for fast climate recovery [2].

BC mostly comprises combustion-generated particles in the range of 20-200 nm formed by the pyrolysis of carbon-containing fuels [8,9]. Other species, such as metals from material wear or heavy organic species such as tar, may also contribute to what is measured as BC [10]. The difficulty in defining BC in terms of its physical or chemical properties has led to its definition-the most complete given by the International Maritime Organization [11] - being based on its strong light absorption properties across all visible wavelengths (e.g., in the order of $5 \mathrm{~m}^{2} / \mathrm{g}$ at $550 \mathrm{~nm}$ ) and its carbonaceous nature. As the physical and chemical properties of BC constantly change during atmospheric aging, its light absorption properties also change significantly enough to affect precise measurements. 
The quantification of $\mathrm{BC}$ also depends on the operational principle used to measure its light absorption properties. As BC is mostly produced by combustion in vehicles, vessels, and stationary burners, its exhaust determination is necessary in order to control and therefore decrease the impact of these emission sources on the environment. Moreover, air quality monitoring of particles by means of sensor networks, which have recently attracted great attention [12,13], relies on sensors that can only detect large particles and exhibit lower accuracy compared to reference instruments [14].

Current particle measurement systems, such as condensation particle counters [15] and those based on electrical charging [16,17] and light scattering (nephelometers) [18], cannot distinguish between BC and other particle species. For distinguishing BC concentrations, optical absorption has been utilized in instruments such as opacimeters [19], aethalometers [19,20], as well as laser-induced incandescence (LII) systems [21]. Opacimeters measure the light extinction of a sample leading to measuring uncertainty due to scattering [22], while their sensitivity is low even for exhaust concentrations $\left(\approx 300 \mu \mathrm{g} / \mathrm{m}^{3}\right)$ [19]. Aethalometers are also affected by the light scattering of $\mathrm{BC}$ or other particles and gases, leading to measurement uncertainty [23]. Moreover, the absorption properties of BC particles change from deposition on the aethalometer filter, due to increased absorption of the scattered light by the soot cake [24]. While a miniaturized aethalometer was recently proposed [25], it was seen to underestimate $\mathrm{BC}$ concentrations with time, probably due to a loading artifact as the same filter is used for several days. For the same reason, it requires frequent maintenance interventions, as the filter needs to be frequently replaced. Finally, LII systems require high energy light sources to heat BC particles up to $4000 \mathrm{~K}$ [21], thus rendering the technology undesirable for a low-cost sensor.

Optoacoustic (also photoacoustic, OptA) sensors make use of the absorbed energy to create sound, thus achieving a signal that is proportional to light absorption [26]. Compared to other principles, the OptA principle has the greatest potential for accurate $\mathrm{BC}$ monitoring, with the operation principle falling in line with the $\mathrm{BC}$ definition based on its strong light absorption. However, significant size and cost reductions are still necessary before the technology can be implemented for large-scale environmental monitoring and source emission characterization. With current implementations of OptA devices for pollutants measurement, such as the AVL Micro Soot Sensor (MSS) [27], this is not possible, in particular because of the significant laser power required to achieve the necessary sensitivity. In addition, complex flow paths and secondary air flows are required to protect the sensitive components (optical and sound detectors) from contamination by the polluted sample flow. A recently proposed sensor [28] attempted to solve some of these issues by using a Quartz Tuning Fork (QTF) as a sound detector, which increases the sensitivity of the system, thus enabling a cheaper light source. However, this approach still suffers from contamination of the sensitive sound detector that is located in the path of the sample airflow and from the small size of the QTF, which significantly limits the size of the laser beam to approximately $300 \mu \mathrm{m}$ [26]. Thus, possibilities for optimization of the laser beam size are severely limited in most cases.

The current study introduces a miniaturized and low-cost OptA sensor that provides an alternative to high-end equipment for the measurement of $B C$ and potentially other gaseous pollutants. Due to the small size and reduced cost, more applications are available for the developed system such as air quality monitoring by means of a sensor network and an on-board exhaust monitoring system for specific sources. The sensor is based on a novel chamber design that refocuses the generated acoustic energy and by using cheap Laser Diodes (LD) that are overdriven for increased power output. A QTF is used as a sound detector due to its high quality $(\mathrm{Q})$ factor. A prototype able to detect $\mathrm{BC}$ particles and nitrogen dioxide $\left(\mathrm{NO}_{2}\right)$ was manufactured, which is able to perform realtime measurements with fast response to changes in $\mathrm{BC}$ concentration. This novel sensor represents a sensitive and more economic option among existing technologies, with the potential to significantly precipitate environmental pollutant measurements. 


\section{Materials and Methods}

\subsection{Sensor Design}

OptA systems are widely used both in scientific efforts and in commercial applications. All these systems strive to offer the necessary sensitivity. Most OptA systems currently available make use of a cylindrical resonator in order to amplify the generated sound and achieve higher sensitivity [29-31]. By fine-tuning the geometry of the resonator, a significant increase of sensitivity can be achieved [32]. However, only a portion of the acoustic energy is captured by the acoustic detector due to its small area, and such systems exhibit significant dependence on the speed of sound and therefore operation and sample temperature. The AVL MSS that employs such a resonator requires a conditioning unit to control all sample parameters, including temperature. However, this leads to an increase in the size, complexity, and cost of the final system [27]. A different approach to increase the system's sensitivity is to use mirrors in order to increase the light path distance, thus increasing the amount of absorbed light [33]. However, significant effort is required in order to protect the multiple mirrors and/or optical windows from contamination.

Quartz Tuning Forks (QTFs) have been used as sound detectors due to their high Q factor and small size in Quartz Enhanced Photoacoustic Spectroscopy (QEPAS) systems $[26,34,35]$. Systems that use a QTF as a sound detector commonly use either an on-beam or an off-beam configuration. In an on-beam system [26], the laser beam has to be focused between the QTF prongs, which have a distance of approximately $300 \mu \mathrm{m}$. Thus, there are requirements for accurate positioning of the QTF and the laser, and there is minimum potential for optimization of the laser beam size. Additionally, for a particle sensor, contamination of the QTF can result in a change in its resonant frequency with significant impact on the sensor's operation. The off-beam approach overcomes these limitations by using a cylindrical resonator [36]; however, this causes other problems as mentioned above.

Therefore, existing approaches cannot offer the required sensitivity without significant drawbacks. A combination of solutions at different fronts is required to achieve a sensitivity similar to commercial instruments with significantly cheaper components.

In this work, a novel acoustic chamber is implemented that consists of a hollow ellipsoidal cavity [37]. Figure 1a shows a 3D render of the ellipsoidal cavity across the light path. The dimensions of the sensor are also presented and are appropriately scaled to the size of the QTF. The ellipsoid has two focal points (indicated with small red circles in Figure 1a); an acoustic signal generated at one of the two points is reflected off the walls of the ellipsoid and refocused at the other focal point, as demonstrated in Figure 1b. The ellipse has a unique property in that the distance between the first focal point, any point on the walls, and the second focal point is exactly the same. Therefore, ultrasound (US) waves converging at the second focal point have all traveled the exact same distance, independent of the speed of sound, frequency, and pressure, and they interfere constructively and in phase. Supplementary Figure S2 shows a visualization of the sound refocusing. Therefore, one can take advantage of this geometry to focus a laser beam at one focal point and concentrate the acoustic energy at the other focal point at a certain distance away. Thus, a strong signal is achieved, without the use of any resonators or amplifiers.

A constant gas flow is maintained through the acoustic chamber using a pump at the outlet of the sensor. The gas flow enters the chamber through a $2 \mathrm{~mm}$ diameter tube and exits through a $3 \mathrm{~mm}$ diameter tube that is positioned $\approx 6 \mathrm{~mm}$ away, at the other side of the ellipsoid, as shown in Figure 1a,b. In this way, minimal particle diffusion in the chamber is achieved. For $10 \mathrm{~nm}$ particles, the diffusion coefficient is equal to $5.4 \times 10^{-8} \mathrm{~m}^{2} / \mathrm{s}$, while the residence time in the chamber is $\approx 1 \mathrm{~ms}$. These results indicate a mean particle displacement from thermal diffusion of $10 \mu \mathrm{m}$ and estimated particle losses of less than $0.2 \%$ [38].

The gas flow crosses the laser beam at the first focal point. In this way, the detector, which is positioned at the other focal point away from both the light beam and the gas flow, is not being interfered with by the gas flow. The optical windows are positioned 
at the outer surface of the sensor away from the gas flow. The detector and the optical windows are expected to be protected from any contamination and subsequent degradation in sensitivity over time, due to the low particle diffusion achieved by the constant gas flow.

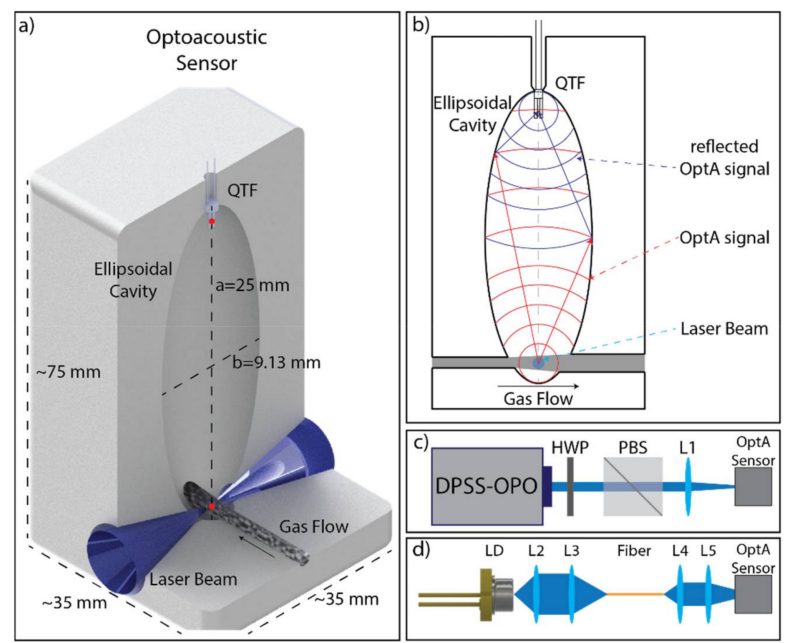

Figure 1. Prototype sensor and experimental setup used in the study. (a) Three-dimensional (3D) render of the acoustic chamber configuration across the light path cross-section and its dimension; (b) A 2D cross-section along the gas flow that shows the generation, reflection, and refocusing of the optoacoustic sound wave on the quartz tuning fork; (c-d) Configuration of the laser excitation systems used; (c) the DPSS-OPO laser setup; (d) the LD excitation system; DPSS-OPO: Diode Pumped Solid State-Optical Parametric Oscillator, HWP: Half-Wave Plate, PBS: Polarizing Beam Splitter; LD: Laser Diode; L1-L5: Lens 1-5.

Moreover, the minimal particle diffusion ensures that there is no OptA signal generated out of the light-gas flow intersection point; i.e., no OptA signal is generated in the tubes that allow light and gas delivery in the chamber. Therefore, the proposed sensor does not act as a resonator as it does not amplify only specific frequencies, but it can be used to refocus the US wave of any frequency from the first focal point to the second. The attenuation of the US is expected to be $\approx 4 \mathrm{~dB} / \mathrm{m}$ at $100 \mathrm{kHz}$ and $\approx 0.8 \mathrm{~dB} / \mathrm{m}$ at $32 \mathrm{kHz}$ [39]. Therefore, the short US travel distance in the ellipsoid $(\approx 50 \mathrm{~mm})$ results in small sound attenuation of $\approx 0.2 \mathrm{~dB}$ at $100 \mathrm{kHz}$.

The ellipsoidal cavity of the prototype sensor demonstrated in the paper was designed and 3D-printed using an Inverse Stereolithography 3D printer (Form2, Formlabs, Somerville, MA, USA). Prototypes for testing were made of a plastic polymer.

A Quartz Tuning Fork (QTF) was selected as the sound detector due to its low cost, small size, and high sensitivity. By the novel design of the acoustic chamber, the usual limitation of the light beam diameter is overcome, and its value can be freely optimized. The two systems (light beam and sound detection) can be optimized independently, resulting in increased capabilities and improved final operation.

Laser Diodes (LD) were used as the light source, as their low cost and small form factor are particularly relevant for miniaturization of the sensor. The low energy output of the LD can be overcome since they can be driven with higher current to provide higher peak power than their continuous wave $(\mathrm{CW})$ nominal values. This provides a significant advantage for OptA imaging and sensing, since the OptA signal requires fast transients [26,40-42]. The ability to use overdriven LD for OptA imaging has been demonstrated in [43]. In the current work, we used an updated version of the laser diode driver to overdrive the CW LD.

\subsection{Experimental Setup}

For the validation of the OptA sensor, we used two different light sources. First, a Diode Pumped Solid State (DPSS) laser equipped with an optical parametric oscillator 
(OPO) laser (Spitlight-DPSS 250 ZHGOPO, InnoLas, Krailing, Germany) providing $10 \mathrm{~ns}$ pulses at a repetition rate of $50 \mathrm{~Hz}$ was used due to its ability to fine-tune the excitation wavelength. The wavelength step was $5 \mathrm{~nm}$, covering a range between 420 and $700 \mathrm{~nm}$. To ensure constant pulse energy, $\approx 2 \mathrm{~mJ}$ per pulse, across all used wavelengths, a half-wave plate (HWP) was mounted on a motorized rotational stage (PRM1Z8, Thorlabs, Newton, NJ, USA), and a polarizing beam splitter (PBS) was used. The laser beam was focused in the OptA sensor, as described above, using a single plano-convex $75 \mathrm{~mm}$ lens (L1, LA1608-A, Thorlabs, Newton, NJ, USA). The setup is shown in Figure 1c. This laser source was used to assess the sensor performance with a well-characterized laser source.

Second, an overdriven CW LD at $462 \mathrm{~nm}$ (L462P1400MM, Thorlabs, Newton, NJ, USA) was used with the custom-made pulsed laser diode driver and controlled by an arbitrary waveform generator (33522B, Keysight, Newton, NJ, USA). The laser diode provided $\approx 7 \mathrm{~ns}$ pulses of $140 \mathrm{~nJ}$ at pulse repetition rates of $\approx 100 \mathrm{kHz}$, tuned to match the central frequency of the QTF. The use of nanosecond pulses ensures that the thermal and stress confinement limits are satisfied [44,45]. This is a low-cost light source that could be used in actual implementation of the sensor. To focus the output of the laser diode into a multimode fiber (M92L02, Thorlabs, Newton, NJ, USA), a two-lens system was used (L2 and L3, C340TMD-A and C560TME-A, Thorlabs, Newton, NJ, USA). The multimode fiber was used to reduce the strong electromagnetic interference generated by the pulsed laser diode driver, when triggered to create the current pulse, by physically creating distance between the driver and the OptA sensor. This also allows for the proper shielding and grounding of all electrical connections of the system, further reducing interference and noise. To focus the output of the fiber in the OptA sensor, a second two-lens system was used (L4 and L5, $15 \mathrm{~mm}$ D., $0.33 \mathrm{NA}$ and $18 \mathrm{~mm}$ D. $\times 8 \mathrm{~mm}$ FL, Edmund Optics, Barrington, NJ, USA). The setup is shown in Figure 1d.

The OptA signal was captured by the QTF (100 kHz, Type TC-26, Conrad, Hirschau, Germany) and amplified by a custom-made amplifier circuit utilizing a dual operational amplifier (AD712D, Analog Devices, Norwood, MA, USA). We used a $100 \mathrm{kHz}$ QTF because OptA signal generation is expected to be more efficient at higher frequencies [44,45]. The amplified signal was recorded using a high-speed digitizer (CSE1222, Dynamic Signals, Lockport, IL, USA), and the digitized signal was processed in Matlab (Matlab 2016b, Mathworks, Natick, MA, USA). The repetition rate of the pulse wave was tuned to be the same as the QTF resonant frequency, f0. The signal was recorded for $1 \mathrm{~s}$ at $500 \mathrm{kS} / \mathrm{s}$. A Fast Fourier Transform (FFT) was performed, and the amplitude of the component at the frequency f0 was recorded. In this way, we perform digital lock-in detection with an effective detection bandwidth of $\Delta \mathrm{f}=1 \mathrm{~Hz}$.

\subsection{Sample Preparation}

A planar 2D burner, operating on diesel, was used to generate $\mathrm{BC}$ particles for the experimental assessment of the sensor, as shown in Figure 2a. After the burner, a mixing chamber is used where the exhaust gas is diluted with clean and dry air. A low dilution ratio is used (1.2-2.5) to reduce the temperature and humidity of the exhaust while maintaining a high particle mass concentration. The sample is then carried to the sensor using conductive tubes. As a reference instrument, we used the Pegasor Particle Sensor (PPS), which determines the particle concentration by charging the suspended particles and measuring the current of the escaping gas flow [17].

At maximum power, the burner normally operates with lean combustion at a lambda value of 1.9. By reducing lambda to 1.6, an increase of both the particle number concentration and mean particle size can be achieved, increasing the overall concentration of BC produced. At such high BC output, lambda is only reduced for a limited amount of time (1-2 min) to prevent the buildup of BC deposits in the soot generation system. The operation with lambda equal to 1.9 is referred to as Normal Operation, and with lambda equal to 1.6 is referred as High Sooting Mode from now on. 


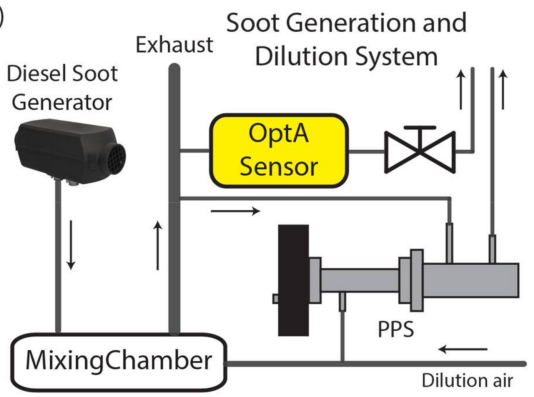

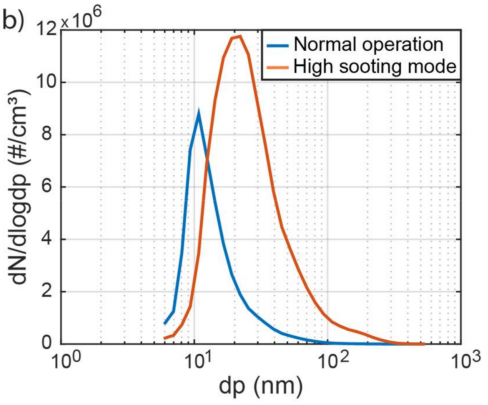

Figure 2. (a) The soot generation and dilution system. (b) The size distribution of particle number for two operation modes of the burner; $\mathrm{dp}$ : particle diameter, $\mathrm{dN} / \mathrm{dlogdp}$ : number of particles in a specific range of particle diameters.

The pollutants concentration at the exhaust of the burner was measured with high-end equipment to determine its composition: a HORIBA Portable Emission Measurement System (PEMS) was used to estimate the concentration of gases and the particle number (PN) concentration, an Engine Exhaust Particle Sizer (EEPS) was used to measure the particle number distribution, and an AVL MSS was used to measure the BC mass concentration. The composition of the exhaust is presented in Table 1 . PN concentration was determined at $2 \times 10^{6} \mathrm{\#} / \mathrm{cm}^{3}$ and the BC concentration was determined at $100 \mu \mathrm{g} / \mathrm{m}^{3}$ at raw exhaust and Normal Operation. In High Sooting Mode, the BC concentration reached $1 \mathrm{mg} / \mathrm{m}^{3}$, while PN concentration levels were in the order of $1 \times 10^{7} \# / \mathrm{cm}^{3}$. The particle size distribution as measured by EEPS is shown in Figure $2 b$, indicating that particles became larger and increased in concentration with decreasing lambda. The MMS and the PPS were used in parallel to characterize the exhaust gas of the burner and showed good linear correlation between them $\left(R^{2}=0.76\right.$, Supplementary Figure $\left.S 1\right)$. In subsequent experiments, we used the PPS because of its portability and ability to provide a fast response time for sensor benchmark analysis.

Table 1. Exhaust gas content of individual pollutants in Normal Operation and High Sooting Mode.

\begin{tabular}{ccc}
\hline Pollutant & $\begin{array}{c}\text { Normal Operation } \\
\lambda=\mathbf{1 . 9}\end{array}$ & $\begin{array}{c}\text { High Sooting Mode } \\
\lambda=\mathbf{1 . 6}\end{array}$ \\
\hline $\mathrm{CO}_{2}(\%)$ & 7.2 & 9.8 \\
\hline $\mathrm{CO}(\mathrm{ppm})$ & 84 & 475 \\
\hline $\mathrm{NO}_{2}(\mathrm{ppm})$ & 7.6 & 9 \\
\hline $\mathrm{NO}(\mathrm{ppm})$ & 44 & 57 \\
\hline $\mathrm{HC}(\mathrm{ppm} \mathrm{C})$ & 0 & 2.2 \\
\hline $\mathrm{PN}[\mathrm{CPC}]\left(\# / \mathrm{cm}^{3}\right)$ & $2.1 \times 10^{6}$ & $1.3 \times 10^{7}$ \\
\hline $\mathrm{BC}[\mathrm{MSS}]\left(\mathrm{mg} / \mathrm{m}^{3}\right)$ & 0.1 & 1.7 \\
\hline
\end{tabular}

$\mathrm{BC}$ absorbs light across the visible region, and Figure 3 shows the theoretical absorption spectrum of BC based on the work of Bond and Bergstrom [24], who proposed an absorption cross-section of $7.5 \mathrm{~m}^{2} / \mathrm{g}$ at a wavelength of $550 \mathrm{~nm}$, and an Angstrom coefficient equal to 1 . In selecting the proper laser wavelength, other species that may also absorb in this range need to be considered. Of the relevant species listed in Figure 2, Figure 3 shows that $\mathrm{NO}_{2}$ absorption resides within the visible range and is stronger for blue light, according to the measurements of Schneider et al. [46]. No other relevant pollutants are expected to absorb significant light intensity in this range. Therefore, when selecting the proper light wavelength, we needed to choose between blue light, which is characterized by a strong $\mathrm{BC}$ signal but also $\mathrm{NO}_{2}$ interference, and red light, which is characterized by lower sensitivity but also zero interference from $\mathrm{NO}_{2}$. To demonstrate the ability of our 
sensor to detect $\mathrm{BC}$, a $\mathrm{LD}$ at the blue wavelength was chosen because it provides higher power compared to a red LD [43].

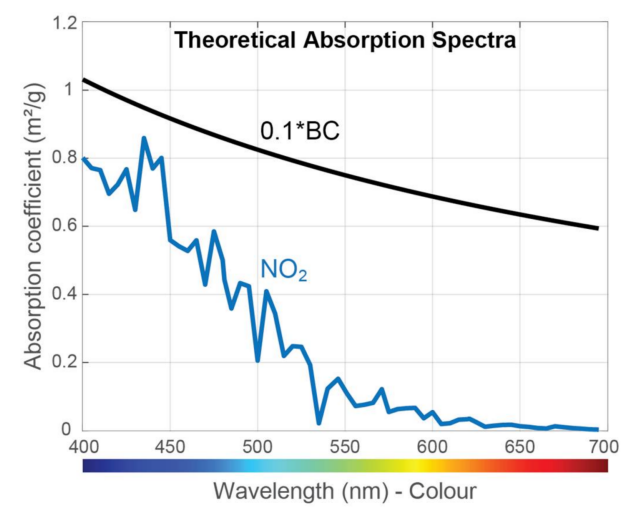

Figure 3. Theoretical light absorption intensity of Black Carbon (BC) together with the absorption potential of $\mathrm{NO}_{2}$ across the visible spectrum.

\section{Results}

The first setup with the DPSS-OPO laser was used in order to evaluate the OptA spectrum of the exhaust gas. As mentioned, light absorption is expected to arise from both $\mathrm{BC}$ particles and $\mathrm{NO}_{2}$. First, we exposed the sensor to unfiltered exhaust to obtain information of total light absorption produced by the exhaust gas, as presented in Figure 4a. Then, in a second experiment (Figure $4 b$ ), we exposed the sensor to exhaust which has been filtered using a High-Efficiency Particulate Air (HEPA) filter with a particle removal efficiency of $>99.9 \%$. In a third experiment (Figure 4c), an Activated Carbon (AC) filter was used to filter out the gaseous components, including $\mathrm{NO}_{2}$. Finally, we exposed the sensor to exhaust which has been filtered using both a HEPA filter and an AC filter in series (Figure 4d), aiming to remove all absorbing species. The burner was set to Normal Operation in all cases, and the SNR of the OptA signal was calculated [47,48].
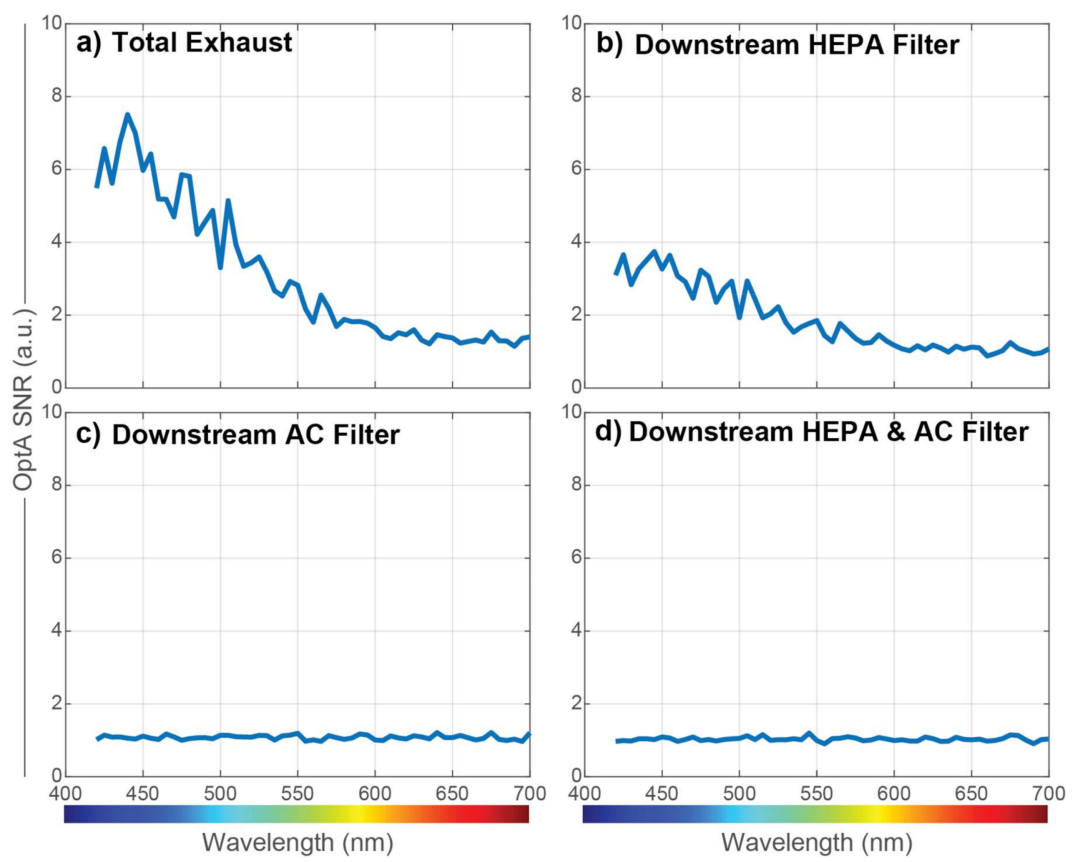

Figure 4. Sensor signal with different exhaust treatment. (a) Total exhaust, (b) Exhaust filtered by a High-Efficiency Particulate Air (HEPA) filter, (c) Exhaust filtered by an Activated Carbon filter, (d) Exhaust filtered by a HEPA filter and an Activated Carbon Filter in series. 
Figure 4a shows the absorption spectrum of both $\mathrm{BC}$ and $\mathrm{NO}_{2}$, while Figure $4 \mathrm{~b}$ shows the spectrum of only $\mathrm{NO}_{2}$, as most particles were captured by the HEPA filter. The absorption in Figure $4 \mathrm{a}$, where both $\mathrm{BC}$ and $\mathrm{NO}_{2}$ are present, was stronger than in Figure $4 \mathrm{~b}$, where only $\mathrm{NO}_{2}$ is present, for all wavelengths. This demonstrates that $\mathrm{BC}$ absorbs in all visible wavelengths, which is in agreement with the theoretical values in Figure 3. No spectra were recorded when the AC filter was used, as it also removes BC at low concentrations. Additionally, the used DPSS laser was emitting pulses at $50 \mathrm{~Hz}$ without the ability to fine-tune its repetition rate, resulting in low sensor sensitivity because no harmonic of its repetition rate coincides with the central frequency of the QTF, as shown below. Finally, with both filters in place and $\mathrm{BC}, \mathrm{NO}_{2}$, and other light absorbing species removed from the flow, the OptA signal was reduced to background levels for all frequencies.

The same experiment for the absorption spectra of the exhaust was performed with a second prototype and gave similar results (data not shown). Both prototypes were assembled by hand without using any micro positioning stages or other mechanism for exact positioning. This indicates that due to the ellipsoidal chamber, the sensor is not sensitive to the exact location of the QTF. This can be explained by the fact that refocusing sound at low frequencies, $10-200 \mathrm{kHz}$, results in a relatively large acoustic focal area, in the order of $\mathrm{mm}$. The size of the OptA focal spot for that frequency is independent of the size of the ellipsoid (Supplementary Figures S2 and S3). As long as the QTF is located in this relatively large focal area, the response of the sensor is not affected.

We next used the second light source, the overdriven LD, to illustrate that such a low-cost light source can be used to detect $\mathrm{BC}$ particles at low concentration. First, the frequency of the light beam was varied by $1 \mathrm{~Hz}$ between 99.7 and $100.3 \mathrm{kHz}$ in order to identify the exact resonant frequency of the QTF and evaluate the sensor's $Q$ factor. This experiment was performed twice: first with clean and dry air and then with the sample from the burner. The signal-to-noise ratio (SNR) was calculated as the amplitude of the particles signal over the standard deviation of the noise at each frequency [47]. The burner was operated in Normal Operation. Figure 5 present the normalized (SNR) of the sensor's response that was almost zero outside of a small interval between approximately 99.9 and $100 \mathrm{kHz}$. The maximum response was at a laser pulse repetition rate of $99.974 \mathrm{~Hz}$. The location of maximum response was a few $\mathrm{Hz}$ lower than $100 \mathrm{kHz}$, since the QTF was operating in air and not in vacuum. The $Q$ factor was calculated by a Gaussian fit of the data to be equal to 3447 , which is approximately $2-3$ times lower than its normal value in atmospheric pressures, which is usually $>10,000[26,47]$. The main reason for this is that the detection bandwidth, $\Delta \mathrm{f}$, of the QTF is relatively large at $\approx 29 \mathrm{~Hz}$ because the proposed sensor does not act as a resonator.

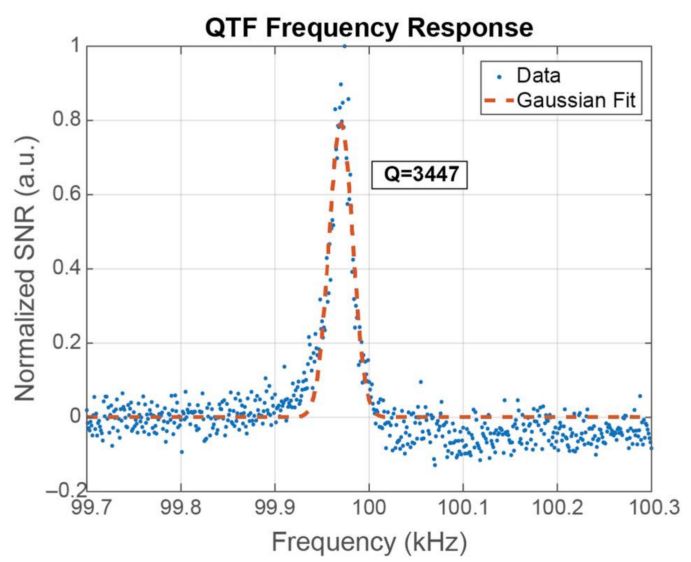

Figure 5. Frequency response of the Quartz Tuning Fork and the sensor's Q factor.

Next, the performance of the sensor was evaluated by operating the burner at High Sooting Mode for $1 \mathrm{~min}$ at a time. During that operation, the $\mathrm{NO}_{2}$ concentration increased 
slightly, while the particle concentration increased by an order of magnitude (Figure 2 and Table 1). The BC concentration was also unstable, leading to significant second-by-second changes. The response of the OptA sensor under such conditions was compared to that of the PPS reference instrument, and the OptA sensor's SNR along with the PPS response are presented in Figure 6. That experiment was initially performed with the activated carbon filter to eliminate the $\mathrm{NO}_{2}$ signal (Figure 6a). The drastic changes in concentration were captured by both instruments equally well, pointing to the excellent performance of the prototype due to its ability to detect changes in concentration in real time and with great accuracy. The same experiment was subsequently performed a second time without using any filters (Figure 6b). A similarly positive performance was observed for the OptA prototype. The signal of the prototype was higher relative to PPS, which is something that can be attributed to the extra response to $\mathrm{NO}_{2}$, which was not completely eliminated.
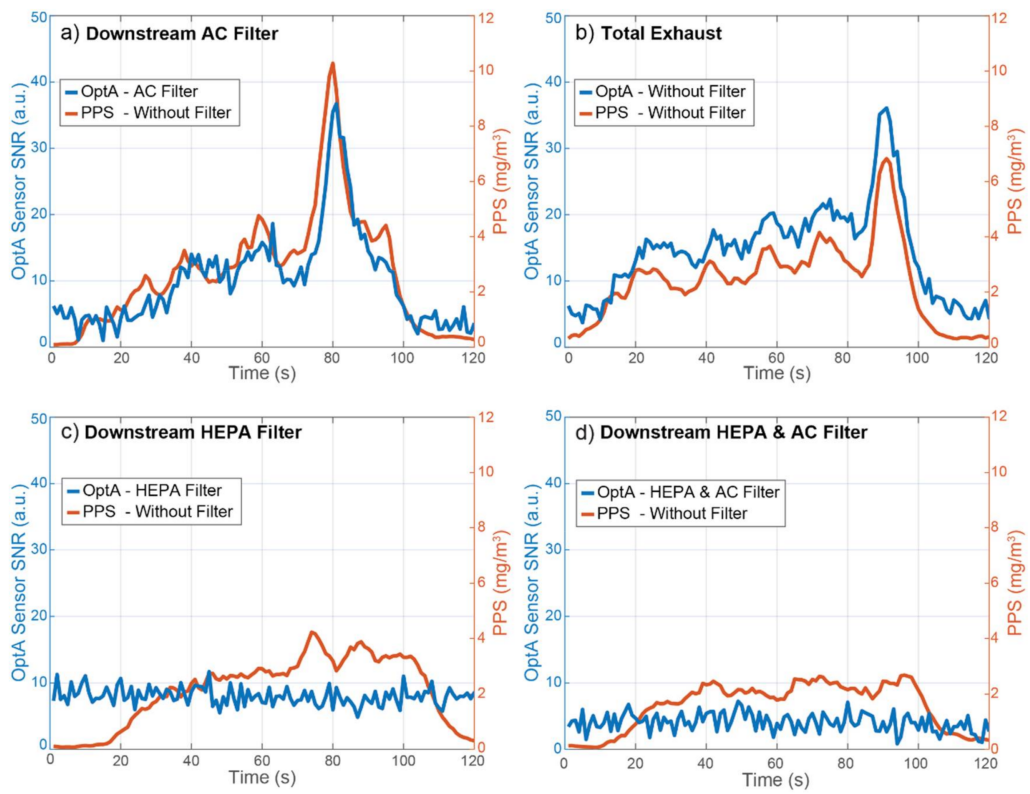

Figure 6. Sensor signal-to-noise ratio (SNR) in High Sooting Mode and comparison with a Pegasor Particle Sensor (PPS), used as a reference instrument. The PPS always received an unfiltered sample. (a) Optoacoustic (OptA) Sensor's sample filtered by an Activated Carbon Filter, (b) total exhaust, (c) OptA sensor's sample filtered by a HEPA filter, (d) OptA sensor's sample filtered by a HEPA filter and an Activated Carbon Filter.

Figure $6 \mathrm{c}$ demonstrates the OptA sensor readings after use of the HEPA filter during a third experiment, which eliminates particles, and the PPS response to the unfiltered sample. An increase in particle concentration similar to Figure $6 a, b$ was observed based on the PPS measurements. However, the OptA sensor's signal remained constant, which can be attributed to $\mathrm{NO}_{2}$, which is stable in High Sooting Mode. Figure $6 \mathrm{c}$ confirms the results, indicating that the signal of the OptA sensor in Figure $6 \mathrm{a}, \mathrm{b}$ was due to particles, since no signal increase was observed when the particles were filtered. Finally, Figure $6 \mathrm{~d}$ shows the response when the OptA sensor was used downstream of both a HEPA and an Activated Carbon Filter during a fourth experiment. A similar curve compared to the previous experiments was seen for the PPS. The OptA sensor had no signal during this experiment.

Finally, the dilution ratio was varied, and 30 consecutive 1-s measurements of the OptA sensor were averaged and compared to the average particle concentration measured by the PPS at the same time to determine the BC detection limit of our sensor. For that experiment, the burner was set to Normal Operation, and the dilution ratio changed from 1.3 to 2.4 . The correlation between the prototype's SNR and the PPS was calculated and plotted along with the data in Figure 7. 


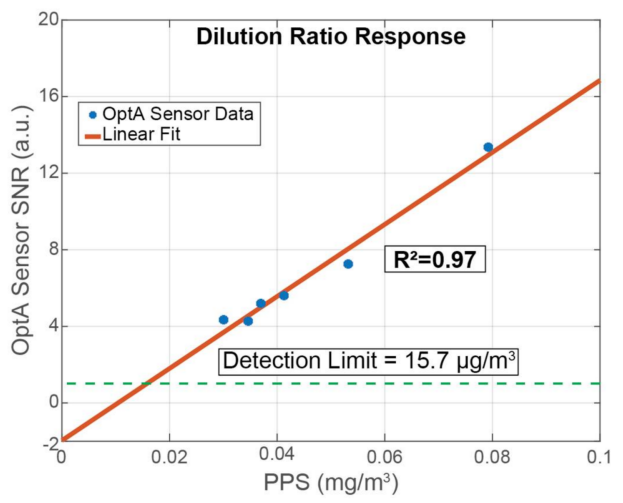

Figure 7. Response of the sensor under different dilution ratios and comparison with the PPS.

The $B C$ concentration varied between 30 and $80 \mu \mathrm{g} / \mathrm{m}^{3}$ depending on the dilution. The present soot generation and dilution system could not achieve a higher dilution or lower concentrations. Higher concentrations were also not possible, as operating the soot generator at High Sooting Mode causes significant and fast changes in the BC concentration and the particle size distribution. No filter was used for that experiment because the AC filter also removes $\mathrm{BC}$ at low concentrations, as shown above; therefore, there was an added response due to $\mathrm{NO}_{2}$. According to the spectra measurements performed above, in Normal Operation Mode, the contribution of $\mathrm{BC}$ in total, from $\mathrm{BC}$ and $\mathrm{NO}_{2}$, was approximately $44 \%$. Additionally, according to the exhaust gas characterization and the correlation between the PPS and the MSS (Supplementary Figure S1), we observed the PPS detecting BC concentrations approximately 4 -fold higher compared to the MSS. This is due to the PPS being calibrated for different particle size distribution. We took into account both these factors to determine the $\mathrm{BC}$ concentration limit.

A good linear correlation was observed with an $R^{2}$ value of 0.97 that can be even higher if a wider concentration range is used. The linear correlation yielded a non-zero offset value $(\approx-2(\mathrm{a} . \mathrm{u}))$ that increases the detection limit, which can be a result of additional noise or interference from other sources that reduce the sensor's SNR. Thus, the normalized noise equivalent absorption coefficient (NNEA) [47] for BC is calculated to be $7.39 \times 10^{-9} \mathrm{~W} \mathrm{~cm}^{-1} \mathrm{~Hz}^{-1 / 2}$ and the Noise Equivalent Concentration (NEC) is calculated to be $15.7 \mu \mathrm{g} / \mathrm{m}^{3}$.

\section{Discussion}

Black Carbon is a pollutant that degrades air quality, is adverse for human health, and significantly contributes to global warming. Despite its tremendous importance, there are currently no low-cost systems for its detection in the field or at an individual source level. In this paper, we presented a novel OptA sensor that can achieve the detection of BC particles at low concentrations and in real time using low-cost components. Such a system can provide a cheap alternative to current instrumentation for a variety of implementations.

Several new features were combined to reduce the size and cost of current OptA technology for BC sensing. First, an ellipsoidal cavity was used to accommodate all the sensor components, which allows for efficient sound detection by concentrating the generated acoustic energy. Second, overdriven Laser Diodes were used to achieve an efficient compromise between cost and high light peak power. Finally, a Quartz Tuning Fork was selected as the sound detector due to its high $\mathrm{Q}$ factor. The manufactured prototype was able to detect $\mathrm{BC}$ and $\mathrm{NO}_{2}$ for the selected laser wavelength and demonstrated a very fast response to changes in concentration. Additionally, two prototypes were assembled by hand and exhibited the same response, indicating that an exact positioning of the sound detector is not required, thus reducing manufacturing effort and minimizing sensitivity to mechanical vibrations.

An additional advantage of the ellipsoidal cavity is that it concentrates acoustic energy rather than amplifying a sound wave. While it increases sensitivity, the use of 
acoustic amplifiers such as resonators in existing applications results in great temperature dependence as the speed of sound varies with temperature. As a result, a conditioning unit is necessary, which increases size, cost, and complexity. By concentrating the acoustic energy, these problems can be overcome because the speed of sound does not influence the focusing ability of the proposed sensor. Moreover, the ellipsoidal design is expected to protect all sensitive components. First, the QTF is located several millimeters away from the gas flow, thus being protected from particle contamination that would affect its long-term operation. Second, the optical path is perpendicular to the gas flow, also limiting $\mathrm{BC}$ deposition on any optical windows and the need for regular cleaning. Finally, the ability to couple the light beam in an optical fiber allows the LD to be further away from the measuring unit. Thus, the ellipsoid can be positioned in a high temperature area without affecting the LD's functionality.

The OptA sensor achieved a detection limit for BC of $15.7 \mu \mathrm{g} / \mathrm{m}^{3}$ and an NNEA of $7.39 \times 10^{-9} \mathrm{~W} \mathrm{~cm}^{-1} \mathrm{~Hz}^{-1 / 2}$, which is comparable to other QEPAS systems that usually achieve an NNEA in the order of $10^{-8}$ to $10^{-10} \mathrm{~W} \mathrm{~cm}^{-1} \mathrm{~Hz}^{-1 / 2}$ [47]. However, the BC detection limit could not be properly characterized due to several factors. The exhaust gas also contained $\mathrm{NO}_{2}$, the contribution of which in the measured SNR had to be mathematically eliminated. In addition, the PPS reference system works on a different principle based on diffusion charging compared to optoacoustic, and its measurements had to be readjusted to fit the MSS measurements. Moreover, the existing dilution system only offered a limited dilution range, which reduced the accuracy of the linear fit. Despite these limitations, the detection limit measured is expected to be in the correct order of magnitude and is considered to be sufficient for a newly developed prototype.

The Q-factor of the sensor was two to three times lower than expected because it refocuses the US rather than acting as a resonator. However, even compared to on-beam QEPAS systems [34], the Q-factor is still lower and might be due to the nature of the $100 \mathrm{kHz}$ QTFs, which have not been extensively tested in QEPAS so far. Future studies will aim at further improving the $Q$ factor and therefore the sensor's sensitivity. The same sensor, with minimal changes, can also be used with a $32 \mathrm{kHz}$ QTF. Additionally, different ellipsoid sizes can be tested and evaluated to reduce the sensor's detection limit. The next steps also include the use of a Lock-in Amplifier, calculation of the Allan deviation to determine the optimal averaging time, and the use of a sensor made from metal to reduce losses when the sound is reflected off the walls of the ellipsoid. Additionally, a multi-wavelength system is also possible, since multiple light beams can be coupled in the same optical fiber. Such a multi-wavelength sensor could be used to detect multiple species simultaneously.

In summary, the developed sensor has the potential to fulfill the function of a sensitive, low-cost BC sensor. Specifically, the cost of the QTF is negligible, while the LD has a maximum cost of a few hundred euros. Conventional light sources typically cost in the order of tenths of thousands of euros, highlighting the tremendous potential for cost reduction of the technology. The final cost for mass production is expected to be in the order of hundreds of euros. The sensitivity of the prototype is calculated to be $15.7 \mu \mathrm{g} / \mathrm{m}^{3}$. By further improving the system, we aim for a detection limit of $1 \mu \mathrm{g} / \mathrm{m}^{3}$ or even lower, which would render the technology adequate for atmospheric measurements.

In addition to improved sensitivity, by proper selection of the wavelength to exclude the $\mathrm{NO}_{2}$ absorption range, one can specifically isolate $\mathrm{BC}$, which would be needed for atmospheric sensor networks. Additionally, the prototype is already capable of evaluating the proper function of exhaust post-treatment systems, which require a detection limit of approximately $100 \mu \mathrm{g} / \mathrm{m}^{3}$. For such direct vehicle exhaust applications, selecting blue light would make the sensor responsive to both $\mathrm{BC}$ and $\mathrm{NO}_{2}$. This would be advantageous, because a single sensor could be used as an on-board monitoring device and detect malfunctions of both the particle filter (that would increase $\mathrm{BC}$ ) and the $\mathrm{NO}_{2}$ post-treatment devices. Other wavelengths could be used for other pollutants, for example, $\mathrm{CO}_{2}$ at $1370 \mathrm{~nm}$. It is important to be able to monitor the $\mathrm{CO}_{2}$ emissions of vehicles during 
their operation, but there is currently a lack of low-cost $\mathrm{CO}_{2}$ sensors for measuring exhaust pollutant concentrations. Therefore, the proposed sensor offers promising potential for an array of future environmental monitoring applications.

Supplementary Materials: The following are available online at https://www.mdpi.com/1424-8 220/21/4/1379/s1, Figure S1: Correlation of the Pegasor Particle Sensor (PPS) with the AVL Micro Soot Sensor (MSS) for the measurement of particles that are created from the BC generation system in Normal Operation, Figure S2: Results from the Computational Fluid Dynamics (CFD) simulation that models the propagation of ultrasound waves and the formation of a high-pressure volume at the second focal spot of the ellipse, Figure S3: Size of the acoustic focal area as a function of the ellipse major axis length.

Author Contributions: Conceptualization, L.N. and V.N.; Data curation, A.S. and N.K.; Formal analysis, A.S. and N.K.; Funding acquisition, L.N. and V.N.; Investigation, A.S. and N.K.; Methodology, A.S., N.K. and A.K.; Software, A.S. and N.K.; Supervision, L.N. and V.N.; Validation, A.S. and N.K.; Visualization, A.K., N.K. and A.K.; Writing—original draft, N.K.; Writing—review and editing, A.S., A.K., L.N. and V.N. All authors have read and agreed to the published version of the manuscript.

Funding: This project has received funding from the European Union's Horizon 2020 research and innovation programme under grant agreement No 814893 (SCIPPER) and under grant agreement No 862811 (RSENSE).

Institutional Review Board Statement: Not applicable.

Informed Consent Statement: Not applicable.

Data Availability Statement: The data presented in this study are available in this article and the supplementary information.

Acknowledgments: We thank Sergey Sulima for reviewing the manuscript. We thank Ioannis Raptis for his assistance with the experiments and Konstantinos Konstantinidis for his assistance in the CFD simulations. We would also like to thank the reviewers for their valuable comments that improved the quality of the manuscript.

Conflicts of Interest: The authors declare no conflict of interest. The funders had no role in the design of the study; in the collection, analyses, or interpretation of data; in the writing of the manuscript, or in the decision to publish the results.

Patents: An application for a patent license (GR20200100657) has been submitted for the optoacoustic sensor presented in this paper.

\section{References}

1. Bond, T.C.; Doherty, S.J.; Fahey, D.W.; Forster, P.M.; Berntsen, T.; DeAngelo, B.J.; Flanner, M.G.; Ghan, S.; Kaercher, B.; Koch, D.; et al. Bounding the role of black carbon in the climate system: A scientific assessment. J. Geophys. Res. Atmos. 2013, 118, 5380-5552. [CrossRef]

2. IPCC. Summary for Policymakers_Global Warming of 1.5oC, an IPCC Special Report; World Meteorological Organization: Geneva, Switzerland, 2018; p. 32.

3. Jansen, K.L.; Larson, T.V.; Koenig, J.Q.; Mar, T.F.; Fields, C.; Stewart, J.; Lippmann, M. Associations between Health Effects and Particulate Matter and Black Carbon in Subjects with Respiratory Disease. Environ. Health Perspect. 2005, 113, 1741-1746. [CrossRef] [PubMed]

4. Janssen, N.A.; Gerlofs-Nijland, M.E.; Lanki, T.; Salonen, R.O.; Cassee, F.; Hoek, G.; Fischer, P.; Brunekreef, B.; Krzyzanowski, M. Health Effects of Black Carbon; World Health Organization: Copenhagen, Denmark, 2012.

5. Ramanathan, V.; Carmichael, G. Global and regional climate changes due to black carbon. Nat. Geosci. 2008, 1, 221-227. [CrossRef]

6. Rosen, H.; Hansen, A.D.A. Role of combustion-generated carbon particles in the absorption of solar radiation in the arctic haze. Geophys. Res. Lett. 1984, 11, 461-464. [CrossRef]

7. Flanner, M.G.; Zender, C.S.; Randerson, J.T.; Rasch, P.J. Present-day climate forcing and response from black carbon in snow. J. Geophys. Res. Space Phys. 2007, 112, 1-17. [CrossRef]

8. Haynes, B.; Wagner, H. Soot formation. Prog. Energy Combust. Sci. 1981, 7, 229-273. [CrossRef]

9. Glassman, I. Soot formation in combustion processes. Symp. (Int.) Combust. 1989, 22, 295-311. [CrossRef]

10. Corbin, J.C.; Mensah, A.A.; Pieber, S.M.; Orasche, J.; Michalke, B.; Zanatta, M.; Czech, H.; Massabò, D.; De Mongeot, F.B.; Mennucci, C.; et al. Trace Metals in Soot and PM2.5 from Heavy-Fuel-Oil Combustion in a Marine Engine. Environ. Sci. Technol. 2018, 52, 6714-6722. [CrossRef] 
11. International Maritime Organization (IMO). Investigation of Appropriate Control Measures (Abatement Technologies) to Reduce Black Carbon Emissions from International Shipping. Third IMO Greenh. Gase Study; International Maritime Organization (IMO): London, UK, 2015.

12. Popoola, O.A.; Carruthers, D.; Lad, C.; Bright, V.B.; Mead, M.I.; Stettler, M.E.; Saffell, J.R.; Jones, R.L. Use of networks of low cost air quality sensors to quantify air quality in urban settings. Atmos. Environ. 2018, 194, 58-70. [CrossRef]

13. Duyzer, J.; Hout, D.V.D.; Zandveld, P.; Van Ratingen, S. Representativeness of air quality monitoring networks. Atmos. Environ. 2015, 104, 88-101. [CrossRef]

14. Jiao, W.; Hagler, G.; Williams, R.; Sharpe, R.; Brown, R.; Garver, D.; Judge, R.; Caudill, M.; Rickard, J.; Davis, M.; et al. Community Air Sensor Network (CAIRSENSE) project: Evaluation of low-cost sensor performance in a suburban environment in the southeastern United States. Atmos. Meas. Tech. 2016, 9, 5281-5292. [CrossRef]

15. TSI. Ultrafine CPC 3776. Available online: https://www.tsi.com/discontinued-products/ultrafine-condensation-particlecounter-3776/ (accessed on 18 November 2020).

16. Ntziachristos, L.; Fragkiadoulakis, P.; Samaras, Z.; Janka, K.; Tikkanen, J. Exhaust Particle Sensor for OBD Application. SAE Tech. Pap. Ser. 2011. [CrossRef]

17. Ntziachristos, L.; Amanatidis, S.; Samaras, Z.; Janka, K.; Tikkanen, J. Application of the Pegasor Particle Sensor for the Measurement of Mass and Particle Number Emissions. SAE Int. J. Fuels Lubr. 2013, 6, 521-531. [CrossRef]

18. Heintzenberg, J.; Charlson, R.J. Design and Applications of the Integrating Nephelometer: A Review. J. Atmos. Ocean. Technol. 1996, 13, 987-1000. [CrossRef]

19. Giechaskiel, B.; Maricq, M.M.; Ntziachristos, L.; Dardiotis, C.; Wang, X.; Axmann, H.; Bergmann, A.; Schindler, W. Review of motor vehicle particulate emissions sampling and measurement: From smoke and filter mass to particle number. J. Aerosol. Sci. 2014, 67, 48-86. [CrossRef]

20. Magee Scientific. Advanced Measurement of Black Carbon; Magee Scientific: Berkeley, CA, USA, 2015; p. 2.

21. Hadef, R.; Geigle, K.P.; Meier, W.; Aigner, M. Soot characterization with laser-induced incandescence applied to a laminar premixed ethylene-air flame. Int. J. Therm. Sci. 2010, 49, 1457-1467. [CrossRef]

22. Mauck, M.; Roessler, D.M.; Faxvog, F.R. Opacity of black smoke: Calculated variation with particle size and refractive index: Erratum. Appl. Opt. 1979, 18, 1-2099. [CrossRef]

23. Bond, T.C.; Anderson, T.L.; Campbell, D. Calibration and Intercomparison of Filter-Based Measurements of Visible Light Absorption by Aerosols. Aerosol Sci. Technol. 1999, 30, 582-600. [CrossRef]

24. Bond, T.C.; Bergstrom, R.W. Light Absorption by Carbonaceous Particles: An Investigative Review. Aerosol Sci. Technol. 2006, 40, 27-67. [CrossRef]

25. Caubel, J.J.; Cados, T.E.; Kirchstetter, T.W. A New Black Carbon Sensor for Dense Air Quality Monitoring Networks. Sensors 2018, 18, 738. [CrossRef]

26. Patimisco, P.; Scamarcio, G.; Tittel, F.K.; Spagnolo, V. Quartz-Enhanced Photoacoustic Spectroscopy: A Review. Sensors 2014, 14, 6165-6206. [CrossRef] [PubMed]

27. AVL. MSS plus. Available online: https://www.avl.com/emission-measurement/-/asset_publisher/gYjUpY19vEA8/content/ mssplus-avl-micro-soot-sensor (accessed on 18 November 2020).

28. Breitegger, P.; Schriefl, M.A.; Nishida, R.T.; Hochgreb, S.; Bergmann, A. Soot mass concentration sensor using quartz-enhanced photoacoustic spectroscopy. Aerosol Sci. Technol. 2019, 53, 971-975. [CrossRef]

29. Miklós, A.; Hess, P.; Bozóki, Z. Application of acoustic resonators in photoacoustic trace gas analysis and metrology. Rev. Sci. Instrum. 2001, 72, 1937-1955. [CrossRef]

30. Elia, A.; Lugarà, P.M.; Di Franco, C.; Spagnolo, V. Photoacoustic Techniques for Trace Gas Sensing Based on Semiconductor Laser Sources. Sensors 2009, 9, 9616-9628. [CrossRef] [PubMed]

31. Petzold, A.; Niessner, R. Photoacoustic soot sensor for in-situ black carbon monitoring. Appl. Phys. A 1996, 63, 191-197. [CrossRef]

32. Kramer, L.; Bozoki, Z.; Niessner, R. Characterisation of a mobile photoacoustic sensor for atmospheric black carbon monitoring Photoacoustic and Photothermal Phenomena-11th International Conference Kyoto, Japan, June 2000. Anal. Sci. 2001, 17, 563-566.

33. Lust, L. Photoacoustic Sensor with Mirrors. U.S. Patent 884,819,1B2, 30 September 2014.

34. Kosterev, A.A.; Bakhirkin, Y.A.; Curl, R.F.; Tittel, F.K. Quartz-enhanced photoacoustic spectroscopy. Opt. Lett. 2002, 27, 1902-1904. [CrossRef]

35. Wu, H.; Dong, L.; Zheng, H.; Yu, Y.; Ma, W.; Zhang, L.; Yin, W.; Xiao, L.; Jia, S.; Tittel, F.K. Beat frequency quartz-enhanced photoacoustic spectroscopy for fast and calibration-free continuous trace-gas monitoring. Nat. Commun. 2017, 8, 15331. [CrossRef]

36. Böttger, S.; Köhring, M.; Willer, U.; Schade, W. Off-beam quartz-enhanced photoacoustic spectroscopy with LEDs. Appl. Phys. A 2013, 113, 227-232. [CrossRef]

37. Shnaiderman, R.; Wissmeyer, G.; Seeger, M.; Soliman, D.; Estrada, H.; Razansky, D.; Rosenthal, A.; Ntziachristos, V. Fiber interferometer for hybrid optical and optoacoustic intravital microscopy. Optics 2017, 4, 1180. [CrossRef]

38. Hinds, W.C. Aerosol Technology: Properties, Behavior, and Measurement of Airborne Particles, 2nd ed.; Wiley: New York, NY, USA, 1999.

39. Goerlitz, H.R. Weather conditions determine attenuation and speed of sound: Environmental limitations for monitoring and analyzing bat echolocation. Ecol. Evol. 2018, 8, 5090-5100. [CrossRef] 
40. Wang, L.V.; Beare, G.K. Photoacoustic microscopy and computed tomography. Biomedical Optics 2008, 14, 171-179. [CrossRef]

41. Wang, L.V.; Hu, S. Photoacoustic Tomography: In-Vivo Imaging from Organelles to Organs. Bone 2012, 335, 1458-1462. [CrossRef]

42. Ntziachristos, V. Going deeper than microscopy: The optical imaging frontier in biology. Nat. Methods 2010, 7, 603-614. [CrossRef]

43. Stylogiannis, A.; Prade, L.; Buehler, A.; Aguirre, J.; Sergiadis, G.; Ntziachristos, V. Continuous wave laser diodes enable fast optoacoustic imaging. Photoacoustics 2018, 9, 31-38. [CrossRef]

44. Wang, L.V. Tutorial on Photoacoustic Microscopy and Computed Tomography. IEEE J. Sel. Top. Quantum Electron. 2008, 14, 171-179. [CrossRef]

45. Tittel, F.K.; Sampaolo, A.; Patimisco, P.; Dong, L.; Geras, A.; Starecki, T.; Spagnolo, V. Analysis of overtone flexural modes operation in quartz-enhanced photoacoustic spectroscopy. Opt. Express 2016, 24, A682-A692. [CrossRef]

46. Schneider, W.; Moortgat, G.K.; Tyndall, G.S.; Burrows, J.P. Absorption cross-sections of NO2 in the UV and visible region (200-700 nm) at 298 K. J. Photochem. Photobiol. A: Chem. 1987, 40, 195-217. [CrossRef]

47. Duquesnoy, M.; Aoust, G.; Melkonian, J.-M.; Lévy, R.; Raybaut, M.; Godard, A. Quartz Enhanced Photoacoustic Spectroscopy Based on a Custom Quartz Tuning Fork. Sensors 2019, 19, 1362. [CrossRef]

48. Zhou, S.; Slaman, M.; Iannuzzi, D. Demonstration of a highly sensitive photoacoustic spectrometer based on a miniaturized all-optical detecting sensor. Opt. Express 2017, 25, 17541. [CrossRef] 